\title{
Re-emerging syphilis: a detrended correspondence analysis of the behaviour of HIV positive and negative gay men C Philip Wheater ${ }^{1}$, Penny A Cook*2, Pete Clark ${ }^{2}$, Qutub Syed ${ }^{3}$ and Mark A Bellis ${ }^{2}$
}

Address: ${ }^{1}$ Department of Environmental and Geographical Sciences, Manchester Metropolitan University, Manchester M1 5GD, UK, 2 Public Health Sector, Liverpool John Moores University, Liverpool L3 2AB, UK and ${ }^{3}$ Communicable Disease Surveillance Centre North West, Vernon Pritchard Court, 57a Upper Northgate Street, Chester CH1 4EF, UK

Email: C Philip Wheater - p.wheater@mmu.ac.uk; Penny A Cook* - p.a.cook@livjm.ac.uk; Pete Clark - p.clark@livjm.ac.uk; Qutub Syed - barbara.jones@hpa.org.uk; Mark A Bellis - m.a.bellis@livjm.ac.uk

* Corresponding author

Published: 29 October 2003

BMC Public Health 2003, 3:34
Received: 17 July 2003

Accepted: 29 October 2003

This article is available from: http://www.biomedcentral.com/I47I-2458/3/34

(C) 2003 Wheater et al; licensee BioMed Central Ltd. This is an Open Access article: verbatim copying and redistribution of this article are permitted in all media for any purpose, provided this notice is preserved along with the article's original URL.

\begin{abstract}
Background: Recent syphilis outbreaks in the UK have raised serious concerns about the sexual health of the population. Moreover, syphilis appears more likely to facilitate HIV transmission than any other sexually transmitted infection (STI).

Methods: The sexual and other risk behaviour of a sample of HIV positive and negative gay men with and without syphilis was subjected to a detrended correspondence analysis (DCA).

Results: A DCA plot was used to illustrate similarity of individuals in terms of their behaviours, regardless of their infection status. The majority of those with syphilis $(78 \%$; $18 / 23)$ fell into a highrisk group with more partners, and use of anonymous sex venues and drugs during sex. However, $16 \%$ of uninfected controls (8/49) and $62 \%$ of HIV positive individuals without syphilis (8/I3) also fell into this high-risk group.
\end{abstract}

Conclusions: Using a statistical technique that is novel for this type of investigation, we demonstrate behavioural overlaps between syphilis-infected individuals in an ongoing UK outbreak and uninfected HIV positive and negative controls. Given the high-risk behaviour of a significant proportion of uninfected individuals, ongoing transmission of syphilis and HIV in this population seems likely.

\section{Background}

Behaviour change among gay men in the early 1980s in response to the AIDS crisis contributed to a reduction in HIV transmission and that of other sexually transmitted infections (STIs) [1]. However, recent increases in STIs and outbreaks of less common STIs such as syphilis amongst gay men in several UK locations $[2,3]$ and elsewhere in Europe [4] raise concerns over complacency about safe sex among gay men. Moreover, STIs such as syphilis may interact with HIV and exacerbate HIV transmission [5].

The largest and most sustained syphilis outbreak in the UK, in Manchester, saw 306 individuals infected between January 1999 and June 2002 [6], at which point the outbreak showed no sign of slowing. The outbreak focuses on homosexual men ( $83 \%$ of cases), and a significant proportion have HIV (29\%) [6]. We previously found that, 
compared to controls without syphilis, individuals infected with syphilis had more partners (particularly oral sex partners) and were more likely to seek partners in anonymous sex venues [7]. However, neither control nor syphilis groups were consistent in using condoms, and many controls had highly risky behaviour. Using a technique not previously used to investigate such an outbreak, we aim to quantify the behavioural overlap between gay men with syphilis (with or without HIV) and those without.

\section{Methods}

Of 58 cases of syphilis presenting at genito-urinary medicine (GUM) departments in Greater Manchester between May 1999 and August 2000, 33 homosexual men (all those whom we were able to contact) were invited to take part and 23 (70\%) gave information on their sexual and social behaviour for 12 months prior to their diagnosis. Three controls were recruited for each case. Controls were recruited through the voluntary sector (44/85 contacts) and directly from known gay social areas (18/42 contacts) and were matched on area of residence (first part postcode), age and ethnicity (all white). Interviews took place between December 2000 and March 2001. Information was gathered using a semi-structured questionnaire. Controls were offered a sexual health check comprising tests for gonorrhoea, syphilis, chlamydia and hepatitis B (and HIV if required) at a GUM department. Of 62 controls, 36 made appointments and 24 were screened: one chlamydia and one hepatitis B case was diagnosed.

Behavioural variables (including sexual and drug taking behaviours and venues used to meet partners) for each individual (irrespective of infection status) were entered into a Detrended Correspondence Analysis (DCA) [8] run through PCOrd verson 4.10 (MjM Software, Oregon, USA) to identify and plot similarities in terms of behaviour between people. This technique was chosen over other ordination techniques because the data were nonlinear (cf principle components analysis), to avoid the arch effect produced when plotting the major axes of variation (cf correspondence analysis), and because of DCA's ability to utilise binary variables (cf multidimensional scaling) [9]. Binary variables were rejected if fewer than ten individuals fell into a category. The rejected variables were: ever injected drugs (8/85 individuals), been paid for sex (5/85 individuals), used a condom for oral sex (3/85 individuals), used crack cocaine (2/85 individuals). DCA produces an ordination plot of major axes of variation in a dataset, which enables a large number of variables to be combined. Commonly the first two major axes of variation are plotted to display all individuals in terms of the similarity (or otherwise) of the variables employed. A discriminant analysis (DA) using SPSS v11 was carried out on the first two ordination axes to aid interpretation of possible groupings between individuals with and without syphilis. Univariate statistics (chi-square and Mann-Whitney U tests) were used to compare the groups predicted by the DA. Individuals are labelled on the plot as to their infection category: those with syphilis alone $(n=16)$, those with syphilis and HIV $(n=7)$, HIV alone $(n=13)$ and those with neither infection $(n=49)$.

\section{Results and discussion}

Once DCA had been used to produce a two-dimensional plot of the major variation in the dataset, individuals were labelled with their infection status (Fig. 1). The closer the points are on the plot, the more similar the individuals' behaviour. Inspection reveals a tight group of individuals towards the left who display similar behaviour. Discrimant analysis indicated that there was a high degree of discrimination between individuals infected with syphilis and those uninfected on the basis of their behaviours. Analysis showed that a higher degree of discrimination (about 77.6\% - see Table 1) was achieved using both ordination axes compared to using the major axis of variation alone $(71.8 \%)$. Two groups can therefore be identified on the ordination biplot (see diagonal line on Fig. 1). The group to the left comprises $88 \%$ of individuals with neither infection, $38 \%$ of those with HIV alone and relatively few individuals with syphilis (22\%). Univariate analysis comparing the two groups reveals that those in the right-hand side of the figure are significantly more likely to have used a variety of drugs: cocaine, poppers, amphetamines, ecstasy viagra and Gamma Hydroxybutyrate (GHB) during sex (Table 2). They were significantly more likely to have met partners in cruising areas (public areas used for sex), cottages (public lavatories) and darkrooms (private rooms in pubs); and were more likely to have met sexual partners abroad. In addition, they had more sexual partners (both oral and anal), and could name fewer of them (Table 3). Groups on the left and right of Fig. 1 did not differ in condom use for anal sex.

The power of the technique is demonstrated by the fact that one of the individuals with both syphilis and HIV who appears on the left of the graph had very few partners and claimed to have been infected with syphilis when forced to perform oral sex. One in eight of those with neither infection and nearly three fifths of HIV positive individuals showed behaviour patterns that were more similar to that of the majority of those with syphilis (i.e. on the right hand side of Fig. 1). These individuals are putting themselves at risk of contracting HIV or other STIs. Indeed, the two controls diagnosed with an STI (chlamydia and hepatitis B) during screening at a GUM clinic following the interview both fall to the extreme right of Fig. 1. This technique provides an objective method of using behaviour to discriminate between infected and uninfected controls and to identify which individuals are 


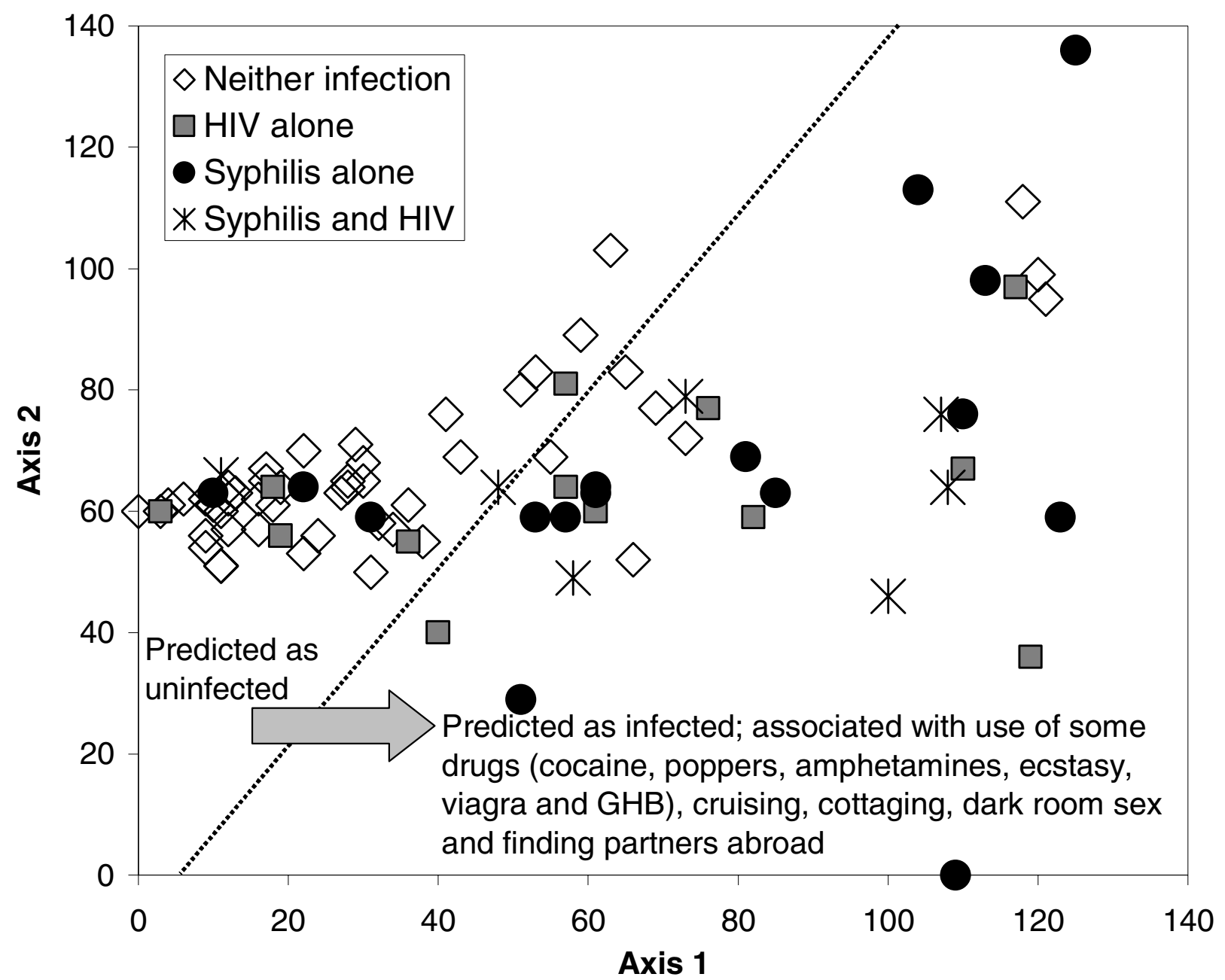

Figure I

Two-dimensional DCA plot showing the major axes of variation in the dataset. The largest source of variation in the dataset is that described by axis I. Individuals closer together on the graph are more similar in their behaviour. The line shows the separation using discriminant analysis based on predicting syphilis-infected individuals.

Table I: Discriminant analysis on the basis of syphilis infected individuals using DCA axis $I$ and axis 2 scores

\begin{tabular}{llcc}
\hline & & Predicted group membership & Totals \\
\cline { 3 - 4 } & & Not infected & Syphilis infected \\
\hline Original group membership & Not infected & $\begin{array}{c}48(77.4 \%) \\
5(21.7 \%)\end{array}$ & $14(22.6 \%)$ \\
& Syphilis infected & $18(78.3 \%)$ & 23 \\
\hline
\end{tabular}

putting themselves at risk. It is particularly useful in analysis of outbreaks of infectious diseases since a relatively large number of binary variables can be combined across a relatively small number of individuals. 
Table 2: Chi square analysis of frequency of behaviour and predicted group membership on the basis of discriminant analysis. Df $=I$ in all cases. Rows in bold are significant at $P<0.05$.

\begin{tabular}{|c|c|c|c|c|}
\hline Behaviour & Chi square value & $P$ & $\begin{array}{r}\text { Percentage of predicted uninfected } \\
\text { exhibiting behaviour } \\
(n=53)\end{array}$ & $\begin{array}{r}\text { Percentage of predicted syphilis infected } \\
\text { group exhibiting behaviour } \\
(n=32)\end{array}$ \\
\hline Paying for sex & 0.027 & 0.870 & 11.3 & 12.5 \\
\hline Using condom during anal sex & 1.637 & 0.201 & 45.3 & 31.3 \\
\hline Using cocaine & 5.647 & 0.017 & 30.2 & 56.3 \\
\hline Using poppers & 6.064 & 0.014 & 71.7 & 93.8 \\
\hline Using alcohol & 2.495 & 0.114 & 98.1 & 90.6 \\
\hline Using amphetamines & 6.574 & 0.010 & 34.0 & 62.5 \\
\hline Using ecstasy & 5.930 & 0.015 & 41.5 & 68.8 \\
\hline Using Viagra & 11.715 & 0.001 & 7.5 & 37.5 \\
\hline Using GHB & 18.827 & $<0.001$ & 18.9 & 65.6 \\
\hline Meeting partners in pubs & 0.096 & 0.756 & 86.8 & 84.4 \\
\hline Meeting partners in clubs & 2.315 & 0.128 & 73.6 & 87.5 \\
\hline Meeting partners in saunas & 0.960 & 0.327 & 45.3 & 56.3 \\
\hline Meeting through cruising & 13.443 & $<0.001$ & 34.0 & 75.0 \\
\hline Meeting through cottaging & 17.805 & $<0.001$ & 13.2 & 56.3 \\
\hline Meeting in dark rooms & 11.384 & 0.001 & 28.3 & 65.6 \\
\hline Meeting through chat rooms & 3.355 & 0.067 & 17.0 & 34.4 \\
\hline Meeting on the internet & 0.113 & 0.737 & 18.9 & 21.9 \\
\hline Meeting partners abroad & 18.093 & $<0.001$ & 5.7 & 43.8 \\
\hline Meeting partners in Manchester & 3.732 & 0.053 & 9.4 & 25.0 \\
\hline
\end{tabular}

Table 3: Mann-Whitney tests between groups predicted to be syphilis infected and uninfected using discriminant analysis on the basis of sexual behaviour.

\begin{tabular}{lrrrr}
\hline Behaviour & $z$ value & $P$ & $\begin{array}{r}\text { Median value for predicted } \\
\text { uninfected group } \\
(n=53)\end{array}$ & $\begin{array}{r}\text { Median value of predicted syphilis } \\
\text { infected group } \\
(n=32)\end{array}$ \\
\hline Number of sexual partners in 12 months & $6.22<0.001$ & 5 & 30 \\
Proportion of names of sexual partners known & $6.90<0.001$ & 60 & 3.5 \\
Number of anal sex partners in I2 months & $3.56<0.001$ & 5 & 10 \\
Number of oral sex in I2 months & $5.39<0.001$ & 30
\end{tabular}

\section{Conclusions}

The recent UK sexual health strategy set new targets for reducing the levels of STIs. However, the Manchester syphilis outbreak continues unabated, raising the possibility that the infection will become endemic. The rate of partner change in the population needs to be high for bacterial sexually transmitted infections to become endemic (since individuals are infectious for only a relatively short period of time) [10]. Here, we have identified high levels of partner change, even among one in eight uninfected HIV negative controls. Interventions are urgently required to address the apparent increase in complacency about safe sex among homosexual men. The at-risk group is variable in terms of potentially risky behaviours (right-hand side of Fig. 1), thus targeting must be flexible. The presence of syphilis in the population may foreshadow an increase in HIV, since those with syphilis are 2 to 5 times more likely to acquire or pass on HIV [5].

\section{List of abbreviations}

DA Discriminant analysis

DCA Detrended Correspondence Analysis

GUM genitourinary medicine

HIV human immunodeficiency virus

STI sexually transmitted infection

UK United Kingdom 


\section{Competing interests}

None declared.

\section{Authors' contributions}

All the authors participated in the design of the study. CPW carried out the Detrended Correspondence Analysis and the discriminant analysis, interpreted the results and drafted the manuscript. PAC assisted in statistical analysis, interpretation of the results and in drafting the manuscript. PC coordinated the study, recruited participants and designed and carried out the questionnaires. MAB and QS conceived the study, and QS provided epidemiological support. MAB assisted in questionnaire design and aided in the interpretation of the results. All authors read and approved the final manuscript.

\section{Acknowledgements}

We thank the staff from the GUM departments of North Manchester General Hospital, Manchester Royal Infirmary and Withington Hospital. The GUM consultants, Steve Higgins, Ashish Sukhankar, Penny Chandiok and Debashis Mandel provided considerable support for this project, as did Diana Leighton (Liverpool John Moores University) and Ann Hoskins, Alan Jones, David McKelvey and Bridget Hughes from Manchester Health Authority. The cooperation of the voluntary organisations Body Positive North West, George House Trust and the Lesbian and Gay Foundation was paramount to recruiting controls. We would also like to thank two referees (Mark Hill and Michael Rekart) for comments on an earlier version of the paper. Finally, we thank all the individuals who sacrificed their time to be interviewed as part of this study. This study was funded by Manchester Health Authority.

\section{References}

I. Nicoll A, Hughes G, Donnelly M, Livingstone S, De Angelis D, Fenton $\mathrm{K}$, Evans B, Gill ON and Catchpole M: Assessing the impact of national anti-HIV sexual health campaigns: trends in the transmission of HIV and other sexually transmitted infections in England. Sex Trans Infect 200I, 77:242-247.

2. Poulton M, Dean GL, Williams DI, Carter P, Iversen A and Fisher M: Surfing with spirochaetes: an ongoing syphilis outbreak in Brighton. Sex Trans Infect 200I, 77:319-321.

3. Fenton KA: Sexual health and HIV positive individuals: emerging lessons from the recent outbreaks of infectious syphilis in England. Commun Dis Public Health 2002, 5:4-6.

4. Doherty L, Fenton K, O'Flanagan D and Couturier E: Evidence for increased transmission of syphilis among homosexual men and heterosexual men and women in Europe. Eurosurveillance Weekly 50:001214. I4 December 2000

5. Fleming DT and Wasserheit JN: From epidemiological synergy to public health policy and practice: the contribution of other sexually transmitted diseases to sexual transmission of HIV infection. Sex Trans Infect 1999, 75:3-17.

6. Clark P, Cook PA, Lighton L, Syed Q and Bellis MA: Syphilis outbreak is twice as big as reported. $B M J$ 2002, 325:775-776.

7. Bellis MA, Cook PA, Clark P, Syed Q and Hoskins A: Re-emerging syphilis in gay men: a case-control study of behavioural risk factors and HIV status. J Epidemiol Comm Health 2002, 56:235-236.

8. Hill MO: DECORANA - A FORTRAN Program for Detrended Correspondence Analysis and Reciprical Averaging. Cornell University, Department of Ecology and Systematics, Ithaca, New York 1979.

9. Digby PGN and Kempton RA: Multivariate analysis of ecological communities London: Chapman and Hall; 1987.

10. Hughes G, Catchpole M, Rogers PA, Brady AR, Kinghorn G, Mercey $D$ and Thin N: Comparison of risk factors for four sexually transmitted infections: results from a study of attenders at three genitourinary medicine clinics in England. Sex Trans Infect 2000, 76:262-267.

\section{Pre-publication history}

The pre-publication history for this paper can be accessed here:

http://www.biomedcentral.com/1471-2458/3/34/prepub
Publish with Bio Med Central and every scientist can read your work free of charge

"BioMed Central will be the most significant development for disseminating the results of biomedical research in our lifetime."

Sir Paul Nurse, Cancer Research UK

Your research papers will be:

- available free of charge to the entire biomedical community

- peer reviewed and published immediately upon acceptance

- cited in PubMed and archived on PubMed Central

- yours - you keep the copyright
BioMedcentral 